\title{
C-reactive protein is a biomarker of AFP-negative HBV-related hepatocellular carcinoma
}

\author{
SHA SHE $^{1 *}$, YI XIANG $^{1 *}$, MIN YANG $^{1}$, XIANGCHUN DING ${ }^{1,4}$, XIAOYAN LIU ${ }^{4}$, LINA MA $^{4}$, QING LIU $^{5}$, \\ BIN LIU ${ }^{5}$, ZHENHUI LU ${ }^{5}$, SHIYING LI ${ }^{1}$, YI LIU ${ }^{1}$, XIAOPING RAN ${ }^{1}$, XIAOMING XU $^{1}$, \\ HUAIDONG HU ${ }^{1-3}$, PENG HU ${ }^{1-3}$, DAZHI ZHANG ${ }^{1-3}$, HONG REN $^{1-3}$ and YIXUAN YANG ${ }^{1}$ \\ ${ }^{1}$ Department of Infectious Diseases, The Second Affiliated Hospital of Chongqing Medical University, \\ Chongqing 400010; ${ }^{2}$ Institute for Viral Hepatitis of Chongqing Medical University, Chongqing 400016; ${ }^{3}$ Key Laboratory \\ of Molecular Biology for Infectious Diseases, Ministry of Education, Chongqing Medical University, Chongqing 400016; \\ ${ }^{4}$ Department of Infectious Diseases, General Hospital of Ningxia Medical University, Yinchuan, Ningxia 750004; \\ ${ }^{5}$ Department of Hepatobiliary Surgery, General Hospital of Ningxia Medical University, \\ Yinchuan, Ningxia 750004, P.R. China
}

Received March 13, 2015; Accepted May 4, 2015

DOI: $10.3892 /$ ijo.2015.3042

\begin{abstract}
Hepatocellular carcinoma (HCC) is one of the most aggressive cancers worldwide and is associated with the high rates of morbidity and mortality. $\alpha$-fetoprotein (AFP) is common used in diagnosis of HCC; however, a growing body of research is questioning the diagnostic power of AFP. There is, therefore, an urgent need to develop additional novel non-invasive techniques for the early diagnosis of HCC, particularly for patients with AFP-negative [AFP(-)] HCC. Accordingly, in the present study, we employed iTRAQ-based mass spectro-metry to analyze the plasma proteins of subjects with AFP(-) HBV-related HCC, AFP(+) HBV-related HCC and non-malignant cirrhosis. We identified 14 aberrantly expressed proteins specific to the HCC patients, including 10 upregulated and 4 downregulated proteins. We verified C-reactive protein (CRP) overexpression by ELISA and immunohistochemical staining of clinical samples. Per ROC curve analyses, CRP was positive in $73.3 \%$ of patients with HBV-related HCC, and CRP overexpression had significant diagnostic power for AFP(-) HBV-related HCC. Furthermore, we found that silencing CRP caused a $>2$-fold decease in $\mathrm{HBV}$ replication. Additionally, we determined that this reduction in HBV replication involved the interferon-signaling pathway. However, silencing CRP also promoted HCC invasion and
\end{abstract}

Correspondence to: Professor Yixuan Yang, Department of Infectious Diseases, The Second Affiliated Hospital of Chongqing Medical University, 76\# Linjiang Road, Chongqing 400010, P.R. China E-mail: yixuan.yang@hotmail.com

*Contributed equally

Key words: hepatocellular carcinoma, $\alpha$-fetoprotein, AFP-negative, $\mathrm{C}$-reactive protein, isotope tags for relative and absolute quantitation migration in vitro. In conclusion, we demonstrated that CRP can serve as a diagnostic biomarker for AFP(-) HBV-related HCC.

\section{Introduction}

Hepatocellular carcinoma (HCC) is one of the most common malignant cancers worldwide with $\sim 598,000$ incidences per year representing the second leading cause of cancer death with the 5 -year survival rate of $<5 \%$ (1).The primary etiological factor for HCC is HBV infection (2); however, inefficient diagnosis of early stage HCC remains a primary causal factor of the high mortality and poor prognosis (3-6). Since the identification of $\alpha$-fetoprotein (AFP) in 1970s, it has been the only serologic marker that is widely used for the HCC diagnosis. However, the diagnostic power of AFP has been continuously questioned and debated. For example, elevated serum AFP was only observed in $\sim 60-70 \%$ of overall HCC patients, while the proportion was merely $33-65 \%$ regarding patients harboring HCCs of $<3 \mathrm{~cm}$ in diameter $(7,8)$. Furthermore, the non-specific elevation of serum AFP was observed in $11-47 \%$ of liver cirrhosis patients $(7,9)$. Although Des-gamma-carboxyprothrombin (DCP) was once proposed to be a better HCC diagnostic marker, investigations have reported that it is only positive in $44-47.6 \%$ of the smaller HCCs $(10,11)$.

Because the best currently available diagnostic HCC markers have significant shortcomings, novel serologic HCC biomarkers that improve the sensitivity and specificity of HCC diagnosis, especially in AFP-negative [AFP(-)] individuals, are greatly needed. In the present study, we define AFP(-) as serum AFP levels $<20 \mathrm{ng} / \mathrm{ml}$.

Several promising HCC biomarkers have been identified using proteomic strategies. For example, Lee et al (12) employed surface-enhanced laser desorption/ionization (SELDI) mass spectrometry (MS) and two-dimensional gel electrophoresis (2DE) technologies and found that comple- 
Table I. Patient demographic and clinical characteristics.

\begin{tabular}{|c|c|c|c|c|c|}
\hline Characteristics & Healthy controls & Chronic hepatitis B & Liver cirrhosis & AFP(-)HCC & $\mathrm{AFP}(+) \mathrm{HCC}$ \\
\hline Age (years), mean $\pm \mathrm{SD}$ & $22 \pm 4.5$ & $42 \pm 13.4$ & $44 \pm 11.9$ & $50 \pm 18.9$ & $55 \pm 20.3$ \\
\hline \multicolumn{6}{|l|}{ Gender } \\
\hline Male & 16 & 22 & 54 & 44 & 32 \\
\hline Female & 24 & 18 & 16 & 30 & 28 \\
\hline ALT (IU/l), mean \pm SD & NA & $453.46 \pm 178.94$ & $108.8 \pm 39.04$ & $26.33 \pm 4.799$ & $47.67 \pm 12.45$ \\
\hline $\operatorname{AFP}(\mathrm{ng} / \mathrm{ml})$, mean $\pm \mathrm{SD}$ & NA & $111.1 \pm 33.89$ & $166.5 \pm 29.56$ & $6.372 \pm 0.495$ & $765.23 \pm 92.28$ \\
\hline HBV DNA $(\log$ copies $/ m l)$, mean \pm SD & NA & $5.67 \pm 1.12$ & $2.87 \pm 0.98$ & $3.12 \pm 1.02$ & $3.33 \pm 1.007$ \\
\hline
\end{tabular}

ment C3a upregulation correlates with the presence of chronic hepatitis $\mathrm{C}$ and hepatitis $\mathrm{C}$ virus (HCV)-related HCC (12). Another study by Feng et al (13) used 2DE and matrix assisted laser desorption/ionization-time of flight tandem mass spectrometry (MALDI-TOF-MS/MS) and identified heat-shock protein 27 (HSP27) as a potential complementary biomarker for AFP to improve the diagnosis of AFP(-) $(<20 \mathrm{ng} / \mathrm{ml}) \mathrm{HCC}$ patients and patients with small HCCs $(<5 \mathrm{~cm})$. Even though gel-based MS provides good visual and physical-chemical information, it is particularly time and labor intensive, with relatively low throughput and can have significant intergel variations (14). Numerous new post-digestion labeling methods, such as isobaric tags for relative and absolute quantitation (iTRAQ) (15-17), have been recommended by the proteomics community to enable deeper proteome coverage and facilitate biomarker discovery.

In the present study, we performed iTRAQ-based MS to quantify differentially expressed proteins (DEPs) between plasma samples from AFP(-) and AFP-positive [AFP(+)] patients. DEPs are also sometimes referred to as 'aberrantly expressed proteins' in this study when we wish to emphasize their biological and/or clinical relevance. Our iTRAQ analysis identified 14 aberrantly expressed proteins specific to the HCC patients. Within this set, ELISA analysis and immunohistochemistry verified the likely importance of C-reactive protein (CRP) overexpression in HCC. Further clinical verification, diagnostic power evaluation and in vitro experiments were performed to validate the importance of CRP overexpression in HCC. We propose that CRP is a potentially useful diagnostic and therapeutic biomarker of AFP(-) HBV-related HCC.

\section{Materials and methods}

Subjects and plasma collection. Two-hundred and eighty-four subjects participated in this study from January 2013 to March 2014, including 74 AFP negative hepatocellular carcinoma patients, 60 AFP positive HCC patients and 70 liver cirrhosis patients, these patients all had chronic hepatitis B infection. There were 40 chronic hepatitis B patients and 40 healthy controls. Serum plasma samples were obtained according to the guidelines given by the HUPO Plasma Proteome Project (18), and $4 \mathrm{ml}$ of peripheral blood was collected from each subject. Diagnoses of chronic hepatitis B, liver cirrhosis and hepatocellular carcinoma were performed according to the Asian Pacific Association for the Study of the Liver
(APASL), the European Association for the Study of the Liver (EASL) and the American Association for the Study of Liver Diseases (AASLD) (19-22). This study was approved by the Ethics Committee of Chongqing Medical University. Written informed consent was obtained from all participants before the treatment. Patient demographics and clinicopathological data are summarized in Table I.

Abundant protein depletion of plasma samples and ITRAQ labeling. Ten randomly chosen individual samples from each group were mixed to create three sample pools (Fig. 1). The most abundant proteins were depleted using an immunodepletion kit (GE Healthcare, Shanghai, China) as per the manufacturer's instructions. Immunodepleted plasma was subjected to protein concentration assays using a 2-D Quant kit (GE Healthcare). Protein $(100 \mu \mathrm{g})$ was precipitated from each pooled group, dissolved in dissolution buffer, denatured, cysteine blocked, digested with $2 \mu \mathrm{g}$ of sequencing grade modified trypsin and labeled using iTRAQ reagents [LC, 113 tag; AFP(-) HCC, 114 tag; and AFP(+) protein, 115 tag] provided by an iTRAQ kit (AB Sciex Analytical Instrument Trading Co., Shanghai, China) (Fig. 1). For the parallel study, the same sample set was labeled with the iTRAQ reagents 116, 117 and 118, respectively (Fig. 1). Peptides from each sample set were mixed prior to subsequent analysis.

Peptide fractionation. Labeled peptides were fractionated by immobilized-pH-gradient isoelectric focusing (IPG-IEF), as previously described $(23,24)$. Briefly, samples were dissolved in a Pharmalyte (GE Healthcare) and urea solution, rehydrated on a pH 3-10 IPG strip, and then subjected to IEF focusing at $68 \mathrm{kV} / \mathrm{h}$ with an IPGphor system (GE Healthcare). Peptides were then extracted from the gel using an acetonitrile (ACN) and formic acid solution (25). The fractions were lyophilized, and purified with SPE Discovery DSC-18 columns (Supelco Inc., Bellefonte, PA, USA). The purified peptides were re-lyophilized and stored at $-20^{\circ} \mathrm{C}$ until use.

MASS spectrometry. Purified peptide fractions were reconstituted in solvent A [water/ACN (98:2 v/v) with $0.1 \%$ formic acid] and separated using a C18-PepMap column (Thermo Fisher Scientific, Beijing, China) with a solvent gradient of 2-100\% Buffer B (0.1\% formic acid and 98\% acetonitrile) in Buffer A at a flow rate of $0.3 \mu \mathrm{l} / \mathrm{min}$. The peptides were electrosprayed using a nanoelectrospray ionization source at an ion spray 
Labeling of plasma samples

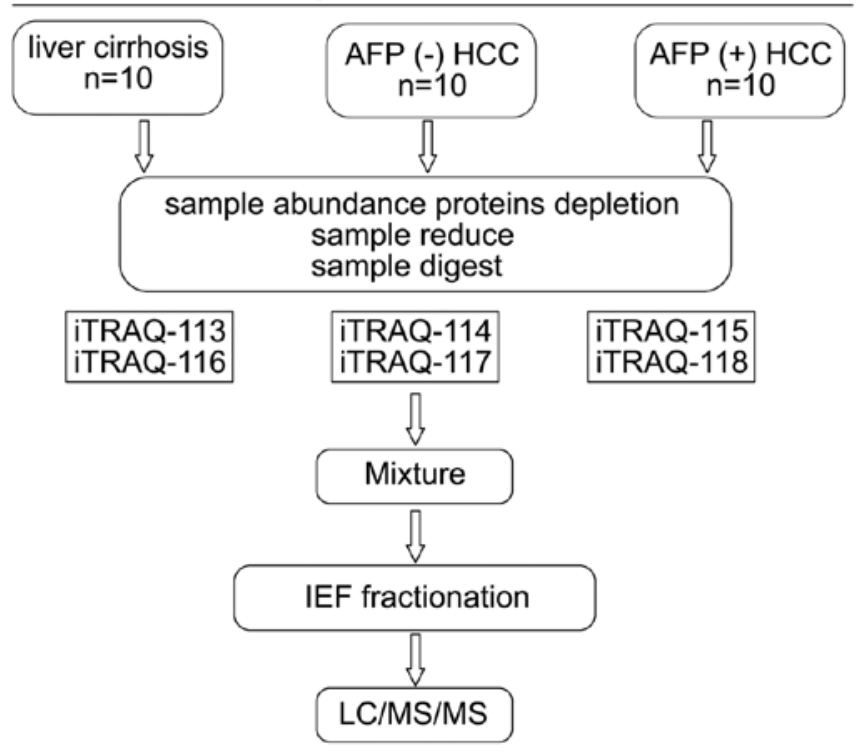

Figure 1. The iTRAQ-based MS workflow.

voltage of $2300 \mathrm{eV}$ and analyzed by a NanoLC-ESI-Triple TOF 5600 system (AB Sciex). The mass spectrometer was set in the positive ion mode at a mass range of $300-1800 \mathrm{~m} / \mathrm{z}$. The two most intensely charged peptides above 20 counts were selected for MS/MS at a dynamic exclusion of $30 \mathrm{sec}$ (25).

Data were processed by ProteinPilot v2.0 (AB Sciex) and compared with the International Protein Index (IPI) Human database v3.77. Cysteine modified by methane thiosulfate (MMTS) was specified as a fixed modification. Protein identification was based on a threshold of protein score $>1.3$. For quantitation, at least two unique peptides with $95 \%$ confidence and a P-value $<0.05$ were required.

Bioinformatics. The Gene Ontology was analyzed by PANTHER (http://www.pantherdb.org/) on biological processes, protein classes and molecular functions. The signaling pathway analysis was performed by using the STRING (http://string-db.org/) program.

ELISA. The plasma levels of CRP, SAA, AFP and C9 were measured in 284 cases using commercial ELISA kits in accordance with the manufacturer's instructions. The cut-off value of CRP was determined using the receiver-operator characteristic curve (ROC) curve, which was twice the SD above the average of the control individuals. Human CRP ELISA kit (ab99995) and Complement C9 Human ELISA kit (ab137972) were purchased from Abcam (Cambridge, UK). The human SAA ELISA kit (ELH-SAA-001) was purchased from Ray Biotech (Norcross, GA, USA).

Tissues microarray and immunohistochemistry (IHC). IHC evaluation of C9, SAA and CRP was performed with a commercial tissue microarray (BC03117; Us Biomax Inc., Rockville, MD, USA) containing 48 unique HCC samples and 22 liver cirrhosis tissues. Paraffin-embedded liver sections were deparaffinized, rehydrated and subjected to heat-induced antigen retrieval in $0.01 \mathrm{M}$ sodium citrate buffer for $5 \mathrm{~min}$ (26).
Next, $3 \% \mathrm{H}_{2} \mathrm{O}_{2}$ was added to quench the activity of endogenous peroxidase for $5 \mathrm{~min}$. After BSA blocking, the sections were incubated overnight with primary antibodies for CRP (1:100), SAA (1:100) and C9 (1:100) (Abcam). The EnVision system with horseradish peroxidase (DakoCytomation, Glostrup, Denmark) was used for IHC visualization (26). Gill's hematoxylin was used to counterstain slides according to methods previously described $(25,26)$. Monoclonal antibodies against human CRP (ab32412), serum amyloid A (SAA, EPR4134), matrix metalloproteinase 2 (MMP2, EPR1184), matrix metalloproteinase 9 (MMP9, EP1254), signal transducer and activator of transcription 3 (STAT3, E121-21), phosphorylated STAT3 (pY705-STAT3, EP2147Y) and $\beta$-actin (EP1123Y) were purchased from Abcam. Horseradish peroxidase (HRP)conjugated secondary antibodies were obtained from Santa Cruz Biotechnology (Dallas, TX, USA).

Cell lines. The stable HBV-transfected cell line HepG2.2.15, the human HCC cell line HepG2 (ATCC, Manassas, VA, USA) and the BEL7402 cell line (Cell Bank of the Chinese Academy of Medical Science, Beijing, China) were cultured in high-glucose DMEM that was supplemented with $100 \mu \mathrm{g} / \mathrm{ml}$ streptomycin, $0.1 \%$ non-essential amino acids, $100 \mathrm{IU} / \mathrm{ml}$ penicillin, $1.0 \mathrm{mM}$ sodium pyruvate, $2 \mathrm{mM}$ glutamine and $10 \%$ FBS at $5 \% \mathrm{CO}_{2}$ and $37^{\circ} \mathrm{C}(27)$.

CRP siRNA transfection, transwell assays and wound healing. Cell lines were transfected with $100 \mathrm{~nm}$ of CRP-specific siRNA (HSS175221, HSS102299 and HSS102300) or a negative control plasmid (12935-400) using Lipofectamine 2000 (Invitrogen, Carlsbad, CA, USA). Cell viability was determined with a trypan blue exclusion assay and only cells that had over $95 \%$ live cells by the trypan blue exclusion assay were used for subsequent assays.

For wound healing assays, cells were cultured in 6-well plates until they reached $100 \%$ confluence. A $200-\mu 1$ pipet tip was used to scratch the cell monolayer, followed by washes with the growth media to remove debris. The resultant gap was monitored for up to $24 \mathrm{~h}$ via a microscope.

Invasion assays were completed by a Cell Invasion assay kit (Cell Biolabs, Inc., Beijing, China). As determined by the trypan blue exclusion, $\sim 1 \times 10^{5}$ viable and siRNA-transfected cells were seeded onto the upper chamber of a 24-well plate with polycarbonate membrane inserts, and the number of cells that invaded through the ECM Matrix gel was determined $24 \mathrm{~h}$ after seeding by CyQuant GR fluorescent dye (560 $\mathrm{nm})$.

Western blotting. Cells were lysed with RIPA buffer, and a 2-D Quantification kit (GE Healthcare) was used to determine the protein concentration. Protein samples were electrophoretically separated by SDS-PAGE and then transferred onto PVDF membranes. Membranes were blocked with BSA in Tris-buffered saline solution with Tween-20 (TBS-T), overnight at $4^{\circ} \mathrm{C}$ and then incubated with the primary antibodies (1:500-1:1,000 dilution) for $3 \mathrm{~h}$ at room temperature. Then membranes were incubated with HRP-conjugated secondary antibodies at a dilution of 1:5,000 after three wahses with TBST buffer. Finally, membranes were visualized with the ChemiDoc MP imaging system (Bio-Rad Laboratories, Hercules, CA, USA). 


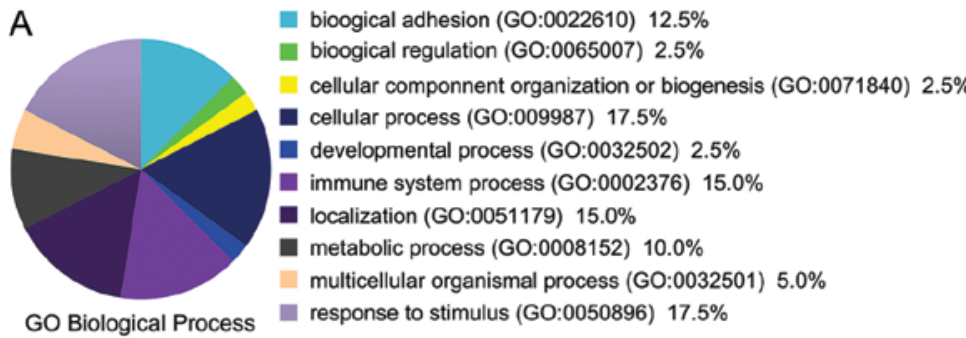

C

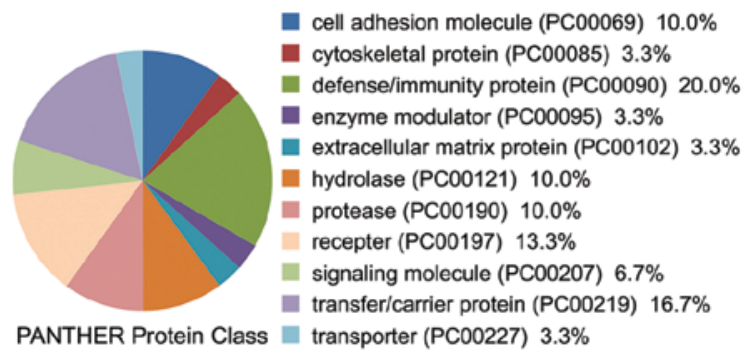

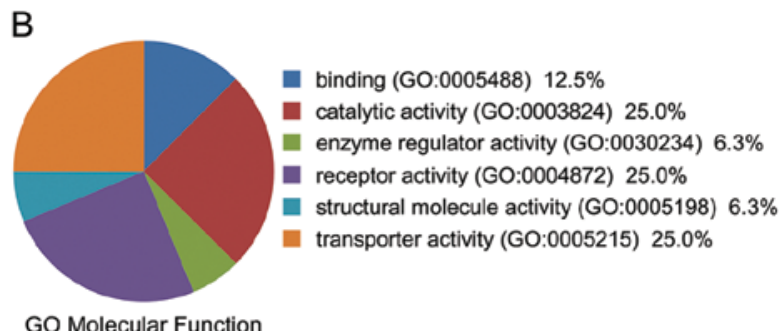

GO Molecular Function

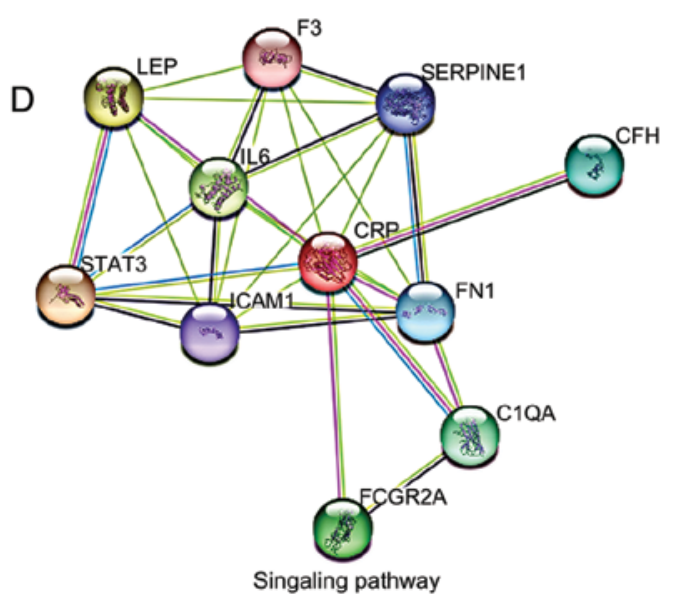

Figure 2. Gene Ontology and STRING analysis. PANTHER analysis of proteins aberrantly expressed in HCC. Proteins were categorized by (A) biological process, (B) protein class and (C) molecular function. (D) STRING analysis.

Supernatant HBV detection and RT-PCR analysis. Supernatant HBV-DNA was quantified by RT-PCR using a commercial HBV detection kit (Fosun Diagnostics, Shanghai, China) on a Roche LightCycler instrument (Roche Molecular Systems, Alameda, CA, USA). Elecsys HBsAg II and HBeAg quantitative assay kits were used to detect $\mathrm{HBsAg}$ and $\mathrm{HBeAg}$ titers, respectively, using the Roche Cobas e601 electrochemical luminescence analyzer (Roche Diagnostics GmbH, Mannheim, Germany) (28). To measure the expression levels of downstream IFN-stimulated genes and type I IFN in transfected cells, we used gene-specific primers for GAPDH (Hs02758991_g1), OASL (Hs00984390_m1), Mx1 (Hs00895608_m1), ISG15 (Hs01921425_s1), OAS2 (Hs00942643_m1), EIF-2 $\alpha$ (Hs00230684_m1), IFN $\beta 1$ (Hs01077958_s1), OAS1 (Hs00973637_m1), PKR (Hs00169345_m1), IFNa1 (Hs00855471_g1) and OAS3 (Hs00196324_m1) (Life Technologies). The $2^{-\Delta \Delta C T}$ method (29) was used to analyze the relative changes in gene expression. All experiments were performed in triplicate.

Statistical analysis. SPSS software v13.0 (SPSS Inc., Chicago, IL, USA) was used to perform statistical analysis. Quantitative variables are presented as the mean and standard deviation $( \pm \mathrm{SD})$. Comparisons between groups were analyzed by the Student's t-test or a Mann-Whitney U test. Qualitative variables are presented as counts and percentages, which were analyzed with the $\chi^{2}$ test. ROC curve analysis of CRP was performed to determine the diagnostic accuracy of CRP expression levels and $2 \mathrm{X} 2$ tables were used to evaluate sensitivity and specificity. Correlations between CRP and HBV DNA were determined using a Spearman's rank correlation analysis. $\mathrm{P}<0.05$ was considered significant.

\section{Results}

MS identification and ITRAQ quantification of aberrantly expressed proteins. We used iTRAQ-based MS to analyze serum proteins from the AFP(-) HCC, AFP(+) HCC and LC groups (Fig. 1). We confidently identified and quantified 510 proteins. The top 30 upregulated and the top 30 downregulated proteins are shown in Table II. We further defined the DEPs using a \pm 1.3 -fold cut-off in accordance with commonly adopted iTRAQ-based MS conventions $(30,31)$. Use of this cut-off is based on the assumption that the estimated overall data variation from duplicate experiments is $\leq 30 \%$. Gene Ontology analysis with PANTHER suggested that the majority of the DEPs were enzymes or signaling molecules, followed by cell development regulators and immune-related proteins (Fig. 2A-C). Using STRING analysis, we identified CRP as the most important node in the DEP network because it had the greatest connectivity (Fig. 2D).

Verification of aberrant CRP, SAA and C9 expression. To determine the reliability of the iTRAQ analysis data, we selected samples from the same sample set we analyzed in the iTRAQ experiments and employed ELISA assays to test the plasma levels of several of the most upregulated proteins, including CRP, SAA and C9. We examined 90 plasma samples from $30 \mathrm{LC}, 30 \mathrm{AFP}(-) \mathrm{HCC}$ and $30 \mathrm{AFP}(+) \mathrm{HCC}$ individuals (Fig. 3A). The ELISA measured CRP, SAA and C9 levels were consistent with the iTRAQ results, as the plasma levels of all three DEPs were significantly higher in $\mathrm{HCC}$ subjects than in LC subjects $(\mathrm{P}<0.05$, Fig. 3A).

We further tested the serum levels of CRP, C9 and SAA in all 284 plasma samples by ELISA (Fig. 3B). We 


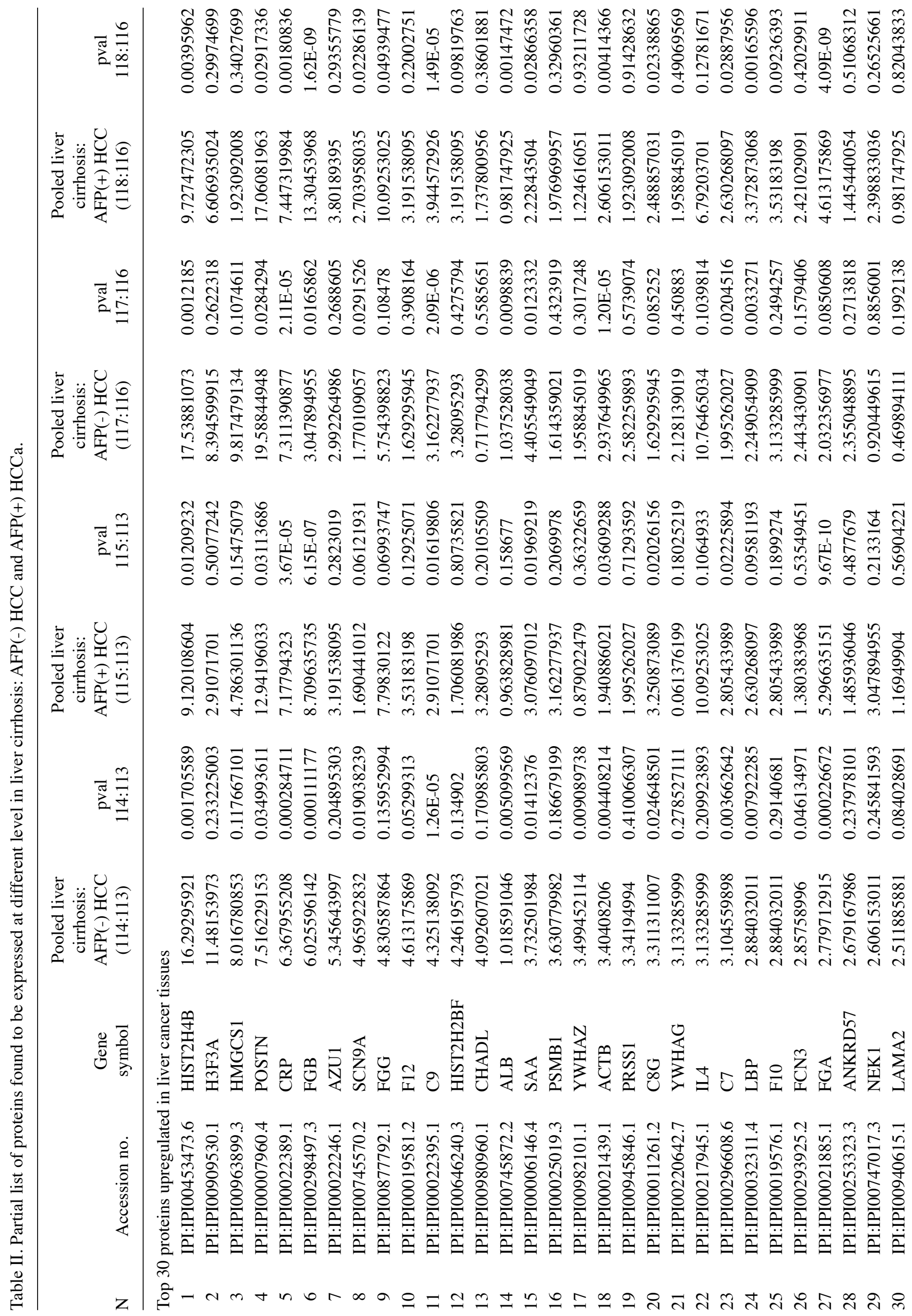




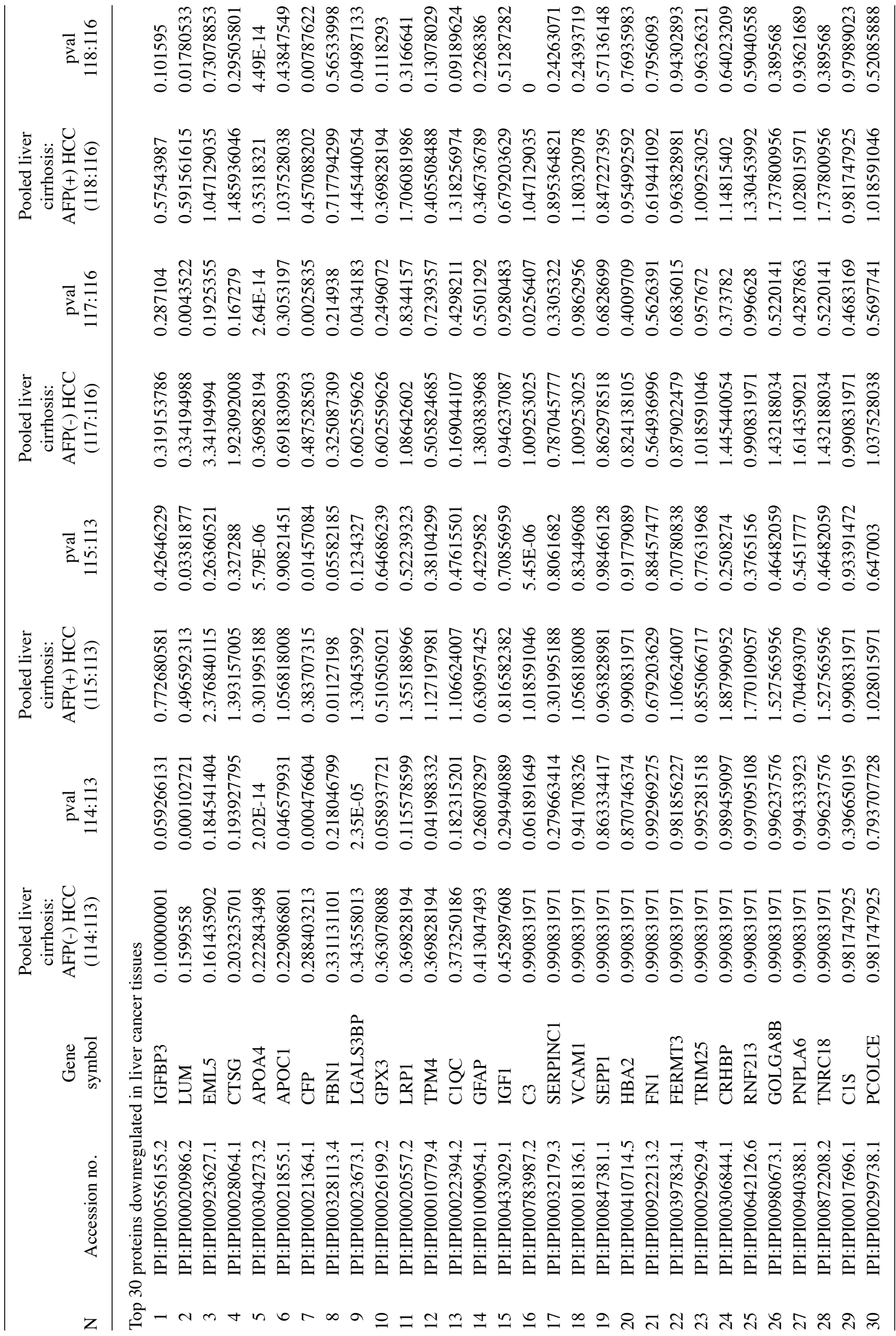


A

B
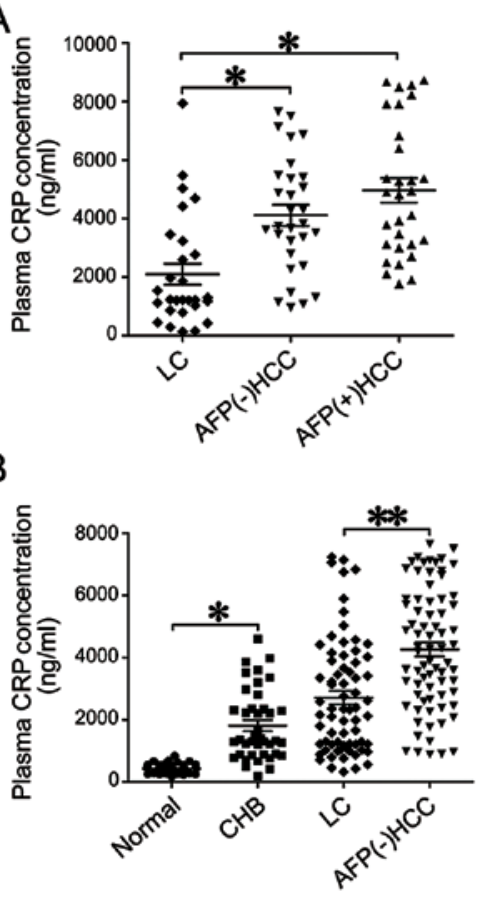

C

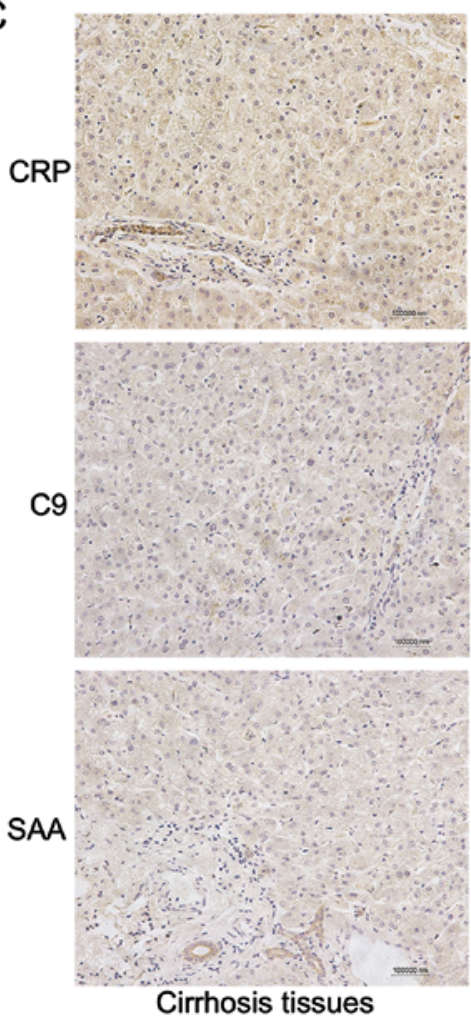

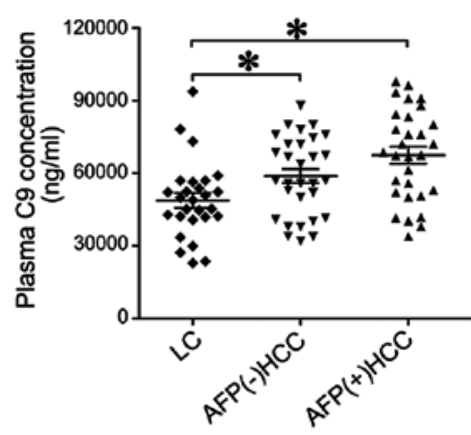
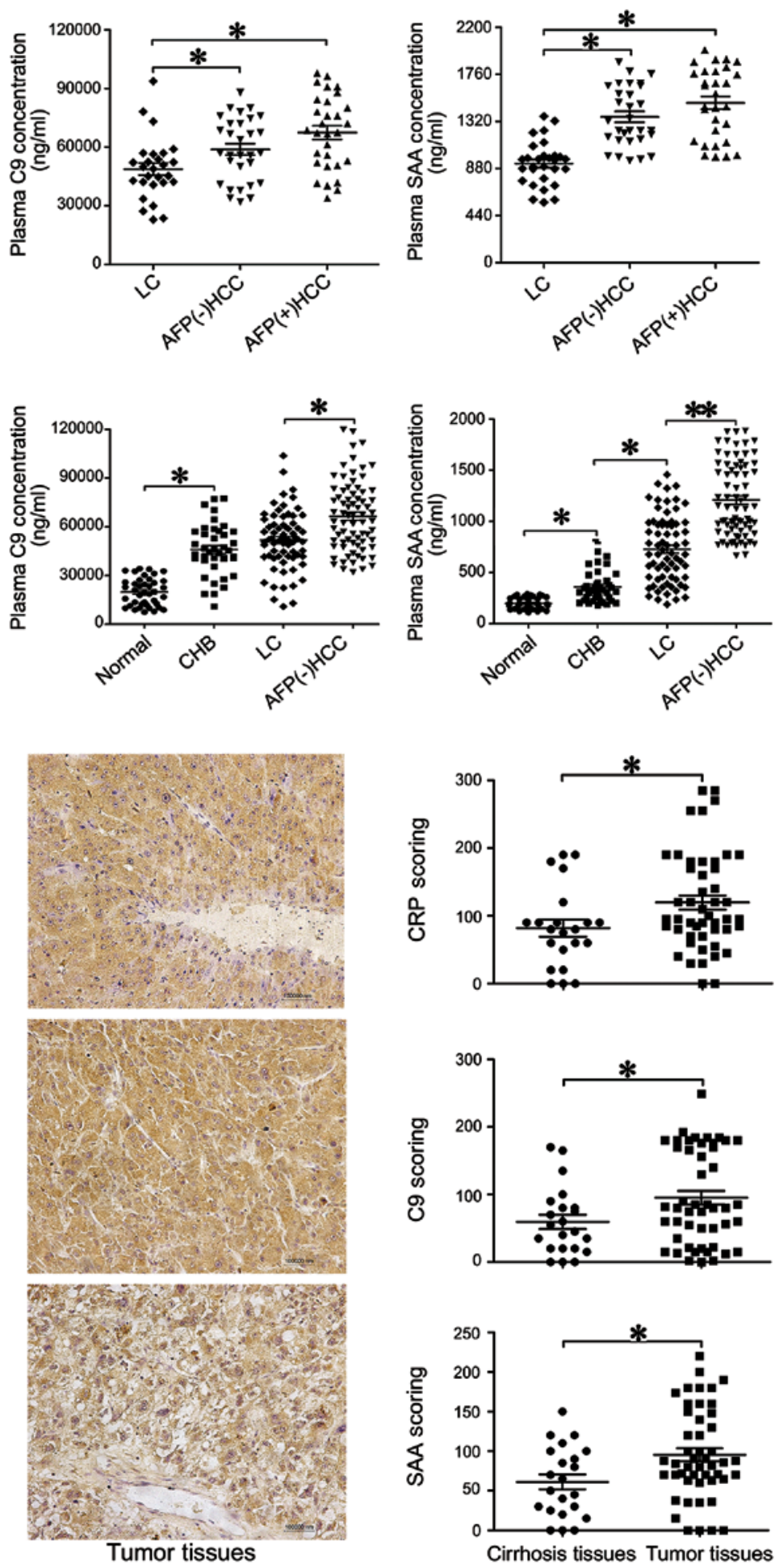

Figure 3. ELISA verification and immunohistochemistry of CRP, C9 and SAA. (A) ELISA verification of iTRAQ results. Samples tested were the same as those used in the iTRAQ experiments. (B) Cohort verification with ELISA. Plasma concentrations of CRP, C9 and SAA were determined in 284 plasma samples. (C) Human tissue microarray and immunohistochemical analysis of CRP, C9 and SAA proteins in cirrhotic and HCC tissues. Scale bar, $100 \mu \mathrm{m}$. Data are shown as mean $\pm \mathrm{SD},{ }^{*} \mathrm{P}<0.05$.

found that average CRP concentrations in the AFP(-) HCC $(3932 \pm 277 \mathrm{ng} / \mathrm{ml})$ and $\mathrm{AFP}(+) \mathrm{HCC}(4860 \pm 384.3 \mathrm{ng} / \mathrm{ml})$ groups were significantly higher than the CRP concentrations in the LC $(2637 \pm 282.4 \mathrm{ng} / \mathrm{ml}, \mathrm{P}<0.001)$, CHB $(1810 \pm 177.9 \mathrm{ng} / \mathrm{ml}$, $\mathrm{P}<0.0001)$ and healthy control $(424.9 \pm 23.95 \mathrm{ng} / \mathrm{ml}, \mathrm{P}<0.0001)$ groups (Fig. 3B). Similar trends were also observed in the SAA and C9 assays (Fig. 3B).
IHC analyses of tissue microarrays coincided with the results of the serum tests, indicating that CRP, SAA and C9 were significantly overexpressed in tumor tissues when compared to cirrhotic tissues $(\mathrm{P}<0.05)$ (Fig. 3C).

Diagnostic power of CRP. Our analysis indicated that CRP was the most important node in the DEP analysis, 

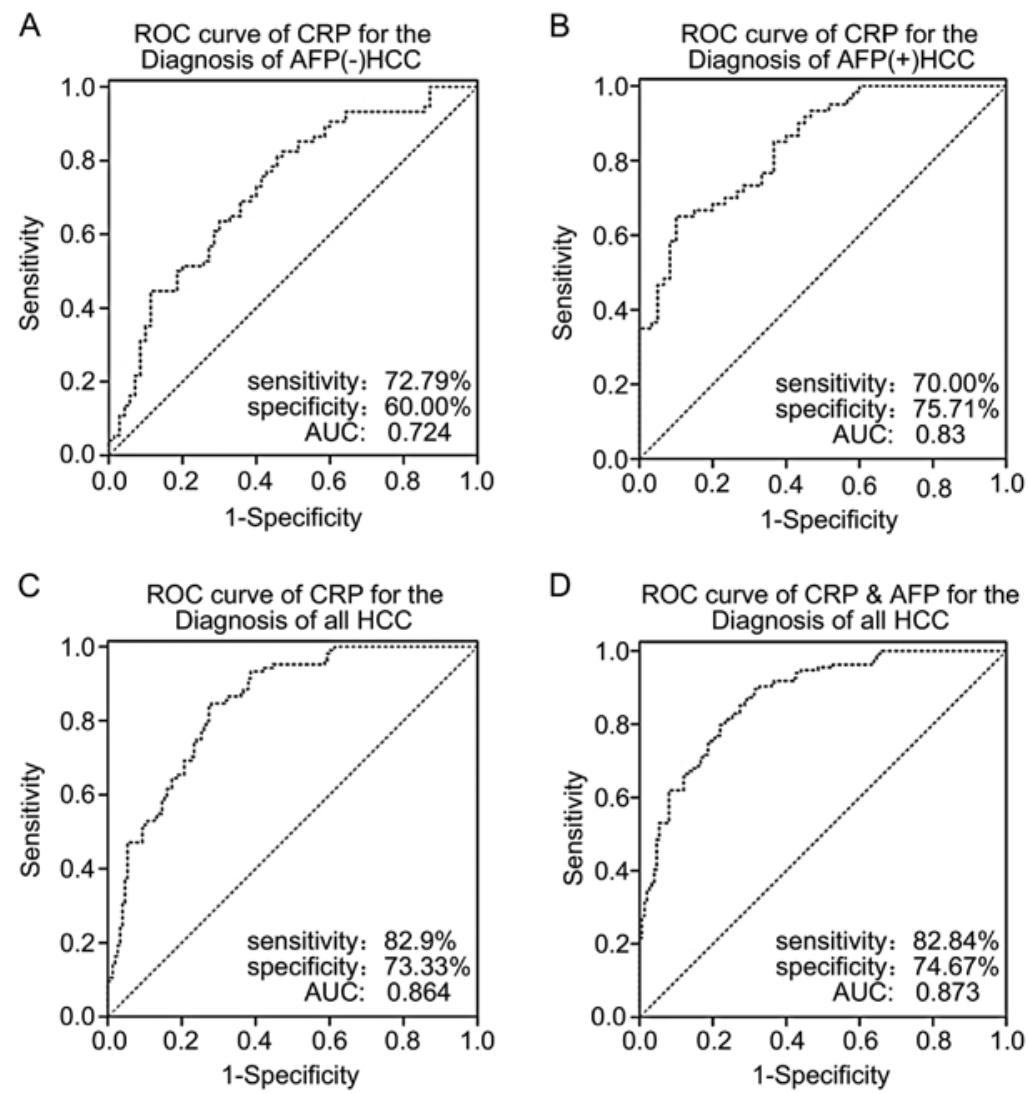

Figure 4. ROC analyses of CRP. (A) The receiver operating characteristic (ROC) curves of CRP in diagnosis HCC of AFP (-) subjects. (B) The receiver operating characteristic (ROC) curves of CRP in diagnosis HCC of AFP (+) subjects. (C) The receiver operating characteristic (ROC) curves of CRP in diagnosis HCC of all subjects. (D) The receiver operating characteristic (ROC) curves of combined CRP and AFP in diagnosis HCC of all subjects.

and IHC analysis confirmed its overexpression in clinical samples. Therefore, we performed ROC analyses to address whether HCC diagnostic tests could be improved by using CRP expression or combined CRP and AFP expression as biomarkers for HCC diagnosis. According to our ROC results, the cut-off value to confirm a positive diagnosis of HCC was $2361.82 \mathrm{ng} / \mathrm{ml}$ for CRP. The sensitivity and specificity for AFP(-) HCC subjects, AFP(+) HCC subjects, all subjects combined were 72.97 and $60 \% ; 70$ and 75.71 and 82.09 and $73.33 \%$, respectively (Fig. 4A-C). The positive predictive values and negative predictive values for all subjects combined, AFP(-) HCC subjects and $\mathrm{AFP}(+) \mathrm{HCC}$ subjects were 73.3 and $82.1 \%$; 65.9 and $67.7 \%$; and 71.2 and $74.6 \%$, respectively. The plasma CRP levels of both the AFP(-) HCC group and all HCC patients combined had significantly higher predictive accuracy than the plasma CRP levels of the LC group. The area under ROC curve (AUC) of CRP in all HCC patients and AFP(-) HCC patients was 0.8642 (95\% CI, 0.819-0.902, $\mathrm{P}<0.01$ ), and 0.724 (95\% CI, 0.643-0.795, $\mathrm{P}=0.0001$ ), respectively (Fig. $4 \mathrm{~A}$ and $\mathrm{C}$ ). When combining CRP with AFP, the AUC was 0.873 (95\% CI, 0.829-0.910, $\mathrm{P}<0.01)$, which was statistically higher than the AUC of AFP alone (AUC=0.812, 95\% CI, 0.763-0.871, P<0.05) (Fig. 4D). It is important to emphasize that $65.9 \%$ of the patients with AFP(-) serum in the present study had elevated CRP.

CRP knockdown promotes HCC cell migration and invasion. To study the role of CRP in tumor cell motility, we silenced
CRP expression in HCC cell lines with CRP-specific siRNA. According to western blot analysis, we found that each of the CRP-specific siRNAs significantly downregulated CRP expression in both HepG2 and BEL7402 cells (Fig. 5A). The assay showed that CRP-specific siRNAs significantly increased the invasion ability of BEL7402 cells and HepG2 by $47-52$ and 40-49\%, respectively $(\mathrm{P}<0.05)$ (Fig. 5B). Additionally, we found that CRP-specific siRNA transfection of BEL7402 cells and HepG2 resulted in a 50-60 and 40-55\% increase in wound healing, respectively $(\mathrm{P}<0.05)$ (Fig. 5B).

CRP knockdown promotes PY705-STAT3, MMP2 and MMP9 protein expression. To examine the functional consequences of aberrant CRP expression, we analyzed the expression levels of the STAT3, pY705-STAT3, MMP2 and MMP9 proteins. These proteins are all known to participate in the pathogenesis of tumor metastasis $(32,33)$. We found that CRP-siRNA transfection resulted in significantly increased expression of pY705-STAT3, MMP2 and MMP9 when compared to control siRNA in both HepG2 and BEL7402 cells (Fig. 6).

The roles of $C R P$ in $H B V$ replication and type I IFN-stimulated gene expression. Considering the prevalence of $\mathrm{HBV}$ infection in HCC patients, we investigated whether CRP expression level is associated with HBV viral load. We observed that CRP plasma levels were positively correlated with HBV-DNA copy number (Pearson $\mathrm{r}=0.571, \mathrm{P}<0.05$ ) (Fig. 7A). Additionally, CRP expression levels were higher in 


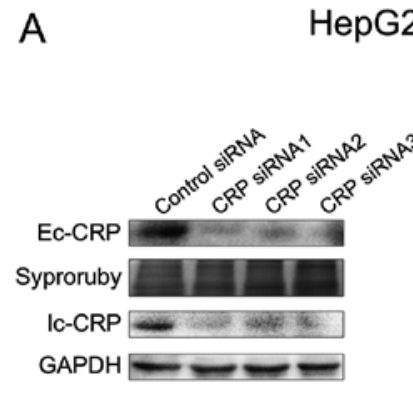

B

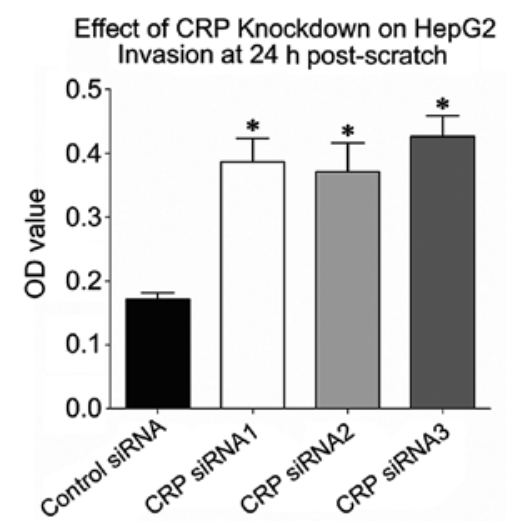

C

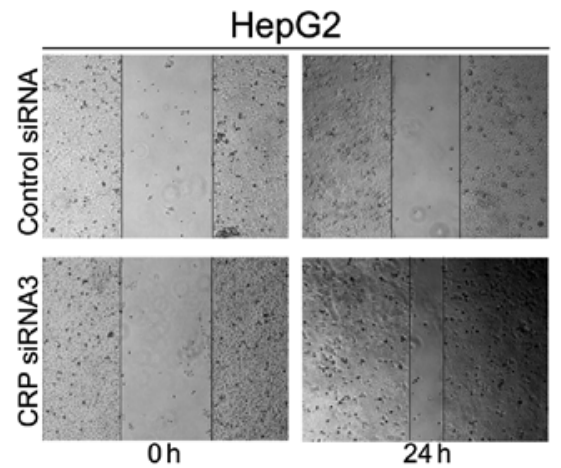

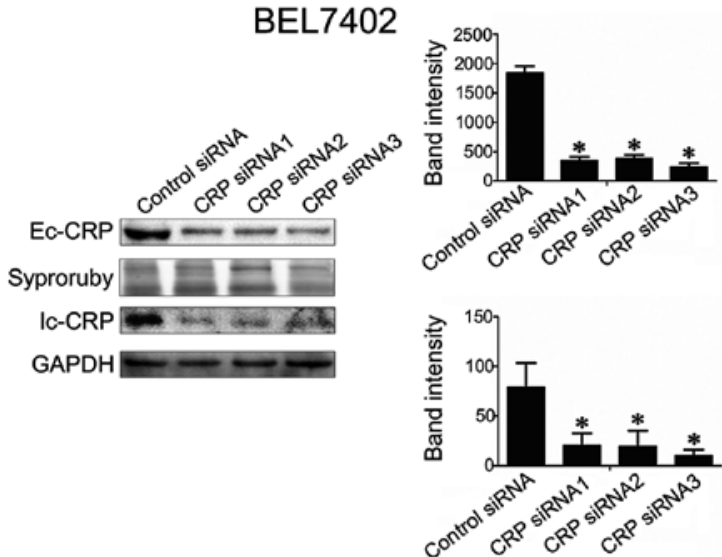
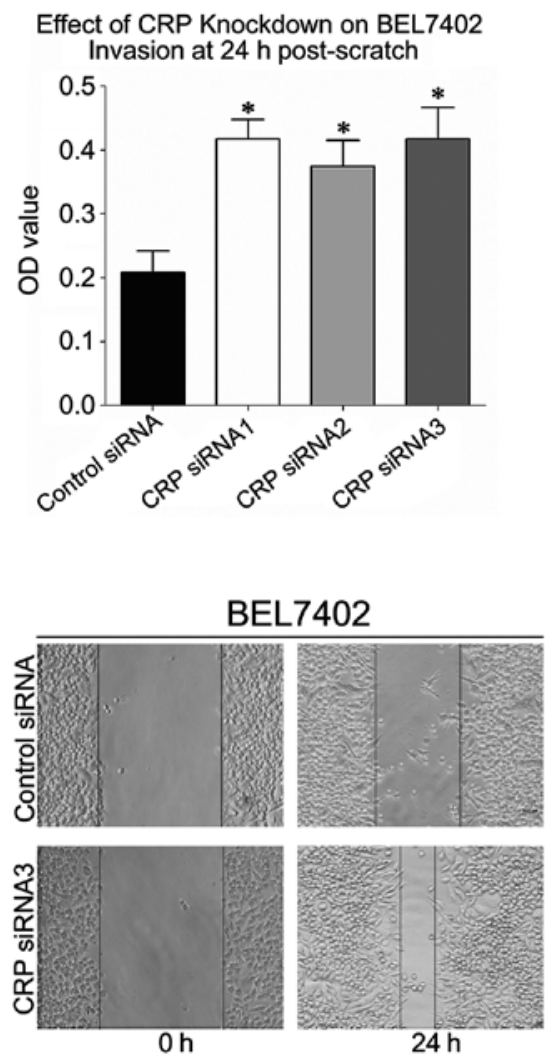

Figure 5. CRP plays important roles in the migration and invasion of HCC cells. (A) Inhibition efficiency evaluation. Cells were transfected with CRP-targeted siRNAs. Western blot analysis of intracellular CRP (Ic-CRP) and extracellular CRP (Ec-CRP) and their respective gray scale analysis results. (B) Invasion assays using CRP-knockdown cells. (C) Wound healing assays using CRP-knockdown cells. Representative images are shown. Scale bar, $100 \mu$ m. Data are shown as mean $\pm \mathrm{SD}$ and ${ }^{*} \mathrm{P}<0.05$.

the plasma of HBV-DNA positive patients than in HBV-DNA negative individuals $(\mathrm{P}<0.05)$ (Fig. 7A). To assess the effect of CRP expression level on HBV replication, we transfected HepG2.2.15 cells, which stably produce HBV-DNA, with CRP specific siRNA. CRP specific siRNA transfection resulted in successful knockdown of both intracellular and extracellular CRP (Fig. 7B). We found that the HBV-DNA titer decreased nearly 2 -fold in the CRP-knockdown groups when compared the control group (Fig. 7C). Furthermore, we determined that CRP knockdown significantly suppressed the transcription of type I IFNs, which are known anti-viral cytokines, and resulted in significant inhibition of genes downstream of IFN, including OAS1, OAS2, OAS3, RNase L and ISG15 ( $\mathrm{P}<0.05)$ (Fig. 7D).

\section{Discussion}

This functional and clinical proteomics study demonstrated that CRP is a promising diagnostic biomarker for AFP(-) and HBV-related HCCs. We observed that CRP has anti-HCC and anti-HBV activities, and that CRP is an indicator of cancerrelated inflammation and HBV infection in HCC.

CRP is an exquisitely sensitive marker of inflammation and tissue damage (34). Elevated CRP expression has been detected in ovarian (35), lung (36) and colon cancer (37). Based on recent studies, the serum CRP levels are correlated with the poor prognosis in many malignancies (37-39). While the molecular mechanism underlying tumor-related CRP elevation in HCC or other cancers remains unknown, several 


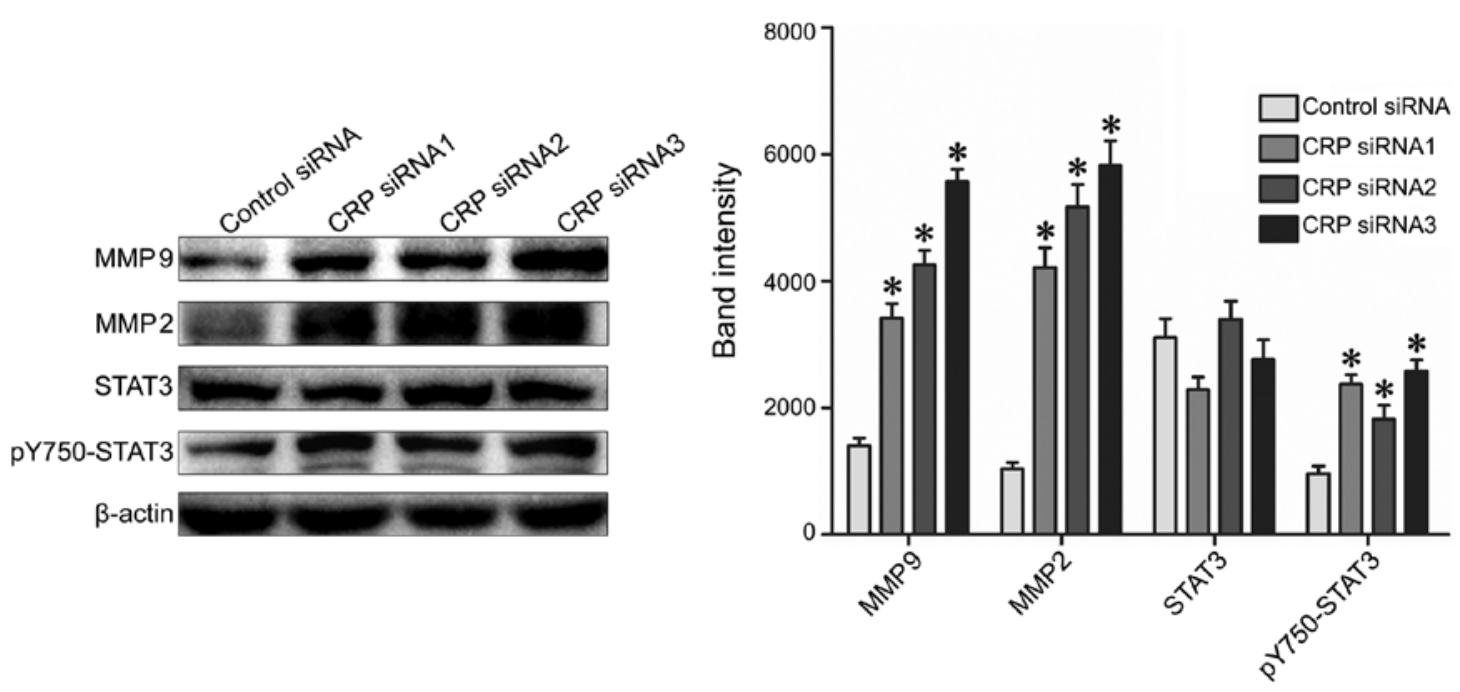

Figure 6. Western blot analyses of STAT3, pY705-STAT3, MMP2 and MMP9. Protein levels from HepG2 cells transfected with CRP-specific or control siRNAs were analyzed by western blot analysis. Data are shown as mean $\pm \mathrm{SD}, \mathrm{P}<0.05$.

A
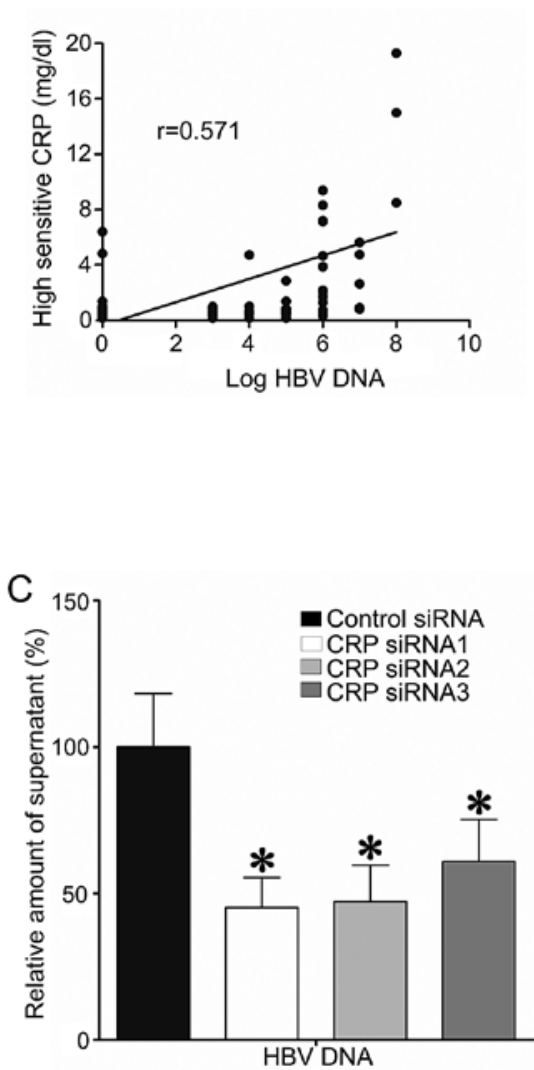

B

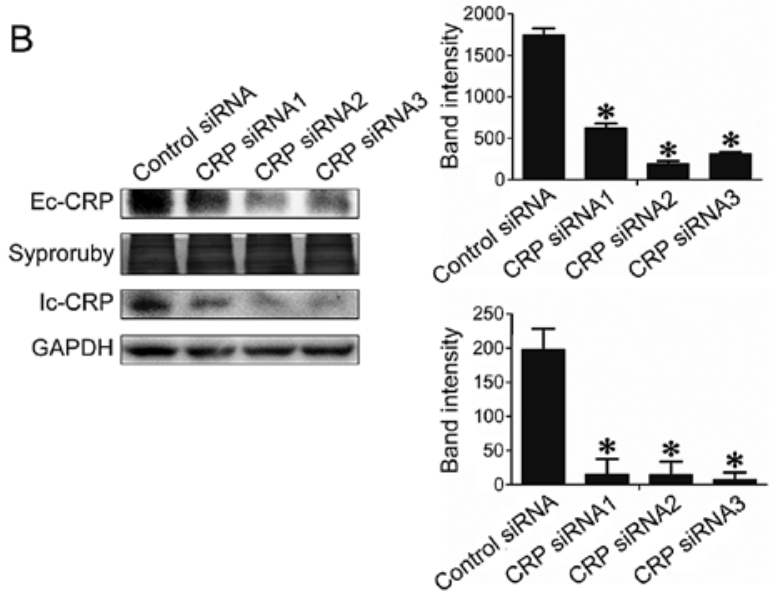

D

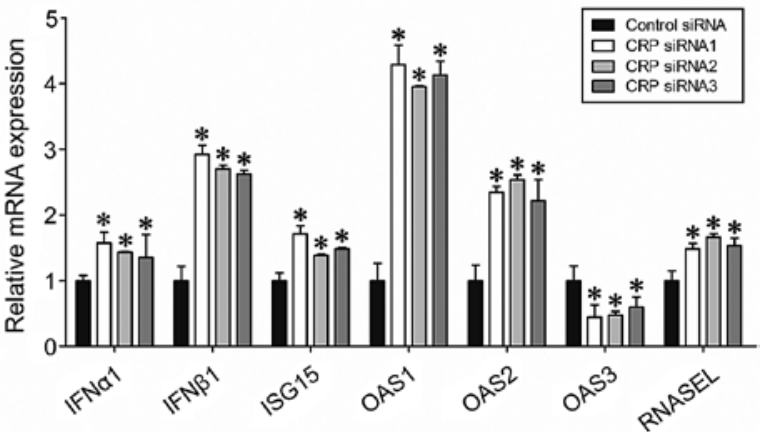

Figure 7. HBV replication and interferon (IFN) signaling related protein expression in CRP-knockdown HCC cells. (A) Correlation of CRP concentration and HBV-DNA copy number. (B) Relative expression of CRP in siRNA knockdown HepG2.2.15 cells. (C) Supernatant HBV copy numbers in the CRP-knockdown cells. (D) RT-PCR analysis of the expression of type I IFN and downstream IFN-stimulated genes.

possible mechanisms have been proposed. For instance, cancer growth and tumor-host cell interaction could increase CRP levels (40). Additionally, CRP levels might reflect an inflammatory response activated as a secondary process in reaction to tumor necrosis or other local tissue damage. Moreover, cancer cells produce cytokines via autocrine pathways, such as
IL-6 and IL-8, which in turn induce CRP production (41). The significance of inflammatory signaling through the STAT3 pathway has been emphasized by numerous studies of HCC and other malignancies $(32,33)$. This helps to contextualize the inhibitory role of CRP described by the presenr study as a host defense mechanism that acts in part by inhibiting STAT3 acti- 
vation and the downstream expression of MMP2 and MMP9. Furthermore, we demonstrated that CRP expression inhibits the migratory and invasive phenotypes of HCC cells.

We observed that serum CRP was positive in $73.3 \%$ of the HCC patients, and, more specifically, in $65.9 \%$ of the AFP(-) $\mathrm{HCC}$ patients. The sensitivity and specificity of CRP expression for HCC diagnosis in AFP(-) HCC subjects was 72.97 and $60 \%$, respectively. Additionally, the sensitivity and specificity of using combined CRP and AFP expression levels for HCC diagnosis (AUC=0.873) was a significant improvement over using AFP expression levels alone $(\mathrm{AUC}=0.812)$. Therefore, CRP could be a useful supplementary biomarker to AFP for HCC diagnosis, especially for AFP(-) HCC. CRP expression has rarely been linked to $\mathrm{HBV}$ infection. Intriguingly, we found a positive correlation between CRP expression and HBV viral load after analyzing the data of 80 chronic HBV infected patients. We further investigated the relationship of CRP and HBV with an in vitro model using HepG2.2.15 cells. The results of these experiments indicated that CRP serves as a pro-viral protein that promotes HBV replication and suppresses anti-viral cytokines.

Because they are both acute-phase proteins similar to CRP, studying the aberrant expression of the SAA and C9 proteins may help increase our understanding of HCC development $(42,43)$. SAA is primarily generated by the liver in response to trauma, infection, inflammation or neoplastic stimuli. It can promote carcinogenesis by activating the transcriptional factor nuclear factor kappa-B (NF- $\kappa \mathrm{B})(44)$ and by inducing the expression of matrix metalloproteinase proteins (MMPs) (45). Li et al (46) reported that SAA affects cell growth and invasion by activating NF- $\kappa \mathrm{B}$ and STAT3 signaling in human (HepG2) and mouse (H22) liver cancer cells.

C9 is the ninth member of the complement components involved in the formation of the membrane attack complex (MAC) (42). Preliminary studies indicate that HCV core proteins attenuate immunity against infection in part by inhibiting C9 and impairing the membrane attack complex (47). Previous proteomics investigations have identified the complement components (C3, C5 and C9) as major serum proteins overexpressed in variety of cancers, including familial aggregative HCC $(48,49)$. However, Ferrin et al $(50)$ recently reported that $\mathrm{C} 9$ was downregulated in $\mathrm{HCV}$-infected $\mathrm{HCC}$ patients, therefore, the role of $\mathrm{C} 9$ in liver tumorigenesis needs further study.

Collectively, we demonstrated a quantitative proteomic profiles of cirrhosis, AFP (-) HBV-associated HCC and AFP (+) HBV-associated HCC. We revealed the correlation between the serum CRP levels and AFP negative HCC patients, and suggest that CRP might participate in the HBV replication. The lack of smaller $(<3 \mathrm{~cm}) \mathrm{HCCs}$, necessitates collection of further tissues and to study the relation between CRP and the smaller $(<3 \mathrm{~cm}) \mathrm{HCCs}$, as our data need further validation with a larger cohort.

\section{Acknowledgements}

The present study was supported by the National Natural Science Foundation of China (nos. 81171560, 30930082, 81171561, 30972584 and 81372399), the National Science and Technology Major Project of China (2008ZX10002-006,
2012ZX1002007001, 2011ZX09302005, 2012ZX09303001001 and 2012ZX10002003).

\section{References}

1. Parkin DM, Bray F, Ferlay J and Pisani P: Global cancer statistics, 2002. CA Cancer J Clin 55: 74-108, 2005.

2. Park NH and Chung YH: Molecular mechanisms of hepatitis B virus-associated hepatocellular carcinoma. Korean J Hepatol 13: 320-340, 2007 (In Korean).

3. Chen CJ, Yang HI, Su J, Jen CL, You SL, Lu SN, Huang GT and Iloeje UH; REVEAL-HBV Study Group: Risk of hepatocellular carcinoma across a biological gradient of serum hepatitis B virus DNA level. JAMA 295: 65-73, 2006.

4. Taylor-Robinson SD, Foster GR, Arora S, Hargreaves S and Thomas HC: Increase in primary liver cancer in the UK, 1979-94. Lancet 350: 1142-1143, 1997.

5. Deuffic S, Poynard T, Buffat L and Valleron AJ: Trends in primary liver cancer. Lancet 351: 214-215, 1998.

6. El-Serag HB and Mason AC: Rising incidence of hepatocellular carcinoma in the United States. N Engl J Med 340: 745-750, 1999.

7. Taketa K: Alpha-fetoprotein: Reevaluation in hepatology. Hepatology 12: 1420-1432, 1990.

8. Chen DS, Sung JL, Sheu JC, Lai MY, How SW, Hsu HC, Lee CS and Wei TC: Serum alpha-fetoprotein in the early stage of human hepatocellular carcinoma. Gastroenterology 86: 1404-1409, 1984.

9. Lok AS and Lai CL: alpha-Fetoprotein monitoring in Chinese patients with chronic hepatitis B virus infection: Role in the early detection of hepatocellular carcinoma. Hepatology 9: 110-115, 1989.

10. Tsai SL, Huang GT, Yang PM, Sheu JC, Sung JL and Chen DS: Plasma des-gamma-carboxyprothrombin in the early stage of hepatocellular carcinoma. Hepatology 11: 481-488, 1990.

11. Soga K, Watanabe T, Aikawa K, Toshima M, Shibasaki K and Aoyagi Y: Serum des-gamma-carboxyprothrombin level by a modified enzyme immunoassay method in hepatocellular carcinoma: Clinical significance in small hepatocellular carcinoma. Hepatogastroenterology 45: 1737-1741, 1998.

12. Lee IN, Chen CH, Sheu JC, Lee HS, Huang GT, Chen DS, Yu CY, Wen CL, Lu FJ and Chow LP: Identification of complement $\mathrm{C} 3 \mathrm{a}$ as a candidate biomarker in human chronic hepatitis $\mathrm{C}$ and HCV-related hepatocellular carcinoma using a proteomics approach. Proteomics 6: 2865-2873, 2006.

13. Feng JT, Liu YK, Song HY, Dai Z, Qin LX, Almofti MR, Fang CY, Lu HJ, Yang PY and Tang ZY: Heat-shock protein 27: A potential biomarker for hepatocellular carcinoma identified by serum proteome analysis. Proteomics 5: 4581-4588, 2005.

14. Görg A, Obermaier C, Boguth G, Harder A, Scheibe B, Wildgruber R and Weiss W: The current state of two-dimensional electrophoresis with immobilized $\mathrm{pH}$ gradients. Electrophoresis 21: 1037-1053, 2000.

15. Gygi SP, Rist B, Gerber SA, Turecek F, Gelb MH and Aebersold R: Quantitative analysis of complex protein mixtures using isotopecoded affinity tags. Nat Biotechnol 17: 994-999, 1999.

16. Mirgorodskaya OA, Kozmin YP, Titov MI, Körner R, Sönksen CP and Roepstorff P: Quantitation of peptides and proteins by matrix-assisted laser desorption/ionization mass spectrometry using ${ }^{18} \mathrm{O}$-labeled internal standards. Rapid Commun Mass Spectrom 14: 1226-1232, 2000.

17. Ross PL, Huang YN, Marchese JN, Williamson B, Parker K, Hattan S, Khainovski N, Pillai S, Dey S, Daniels S, et al: Multiplexed protein quantitation in Saccharomyces cerevisiae using amine-reactive isobaric tagging reagents. Mol Cell Proteomics 3: 1154-1169, 2004.

18. Rai AJ, Gelfand CA, Haywood BC, Warunek DJ, Yi J, Schuchard MD, Mehigh RJ, Cockrill SL, Scott GB, Tammen H, et al: HUPO Plasma Proteome Project specimen collection and handling: Towards the standardization of parameters for plasma proteome samples. Proteomics 5: 3262-3277, 2005.

19. Lok AS and McMahon BJ: Chronic hepatitis B: Update 2009. Hepatology 50: 661-662, 2009.

20. Liaw YF, Leung N, Kao JH, Piratvisuth T, Gane E, Han KH, Guan R, Lau GK and Locarnini S; Chronic Hepatitis B Guideline Working Party of the Asian-Pacific Association for the Study of the Liver: Asian-Pacific consensus statement on the management of chronic hepatitis B: A 2012 update. Hepatol Int 6: 531-561, 2012. 
21. European Association for the Study of the Liver: EASL clinical practice guidelines on the management of ascites, spontaneous bacterial peritonitis, and hepatorenal syndrome in cirrhosis. J Hepatol 53: 397-417, 2010.

22. Bruix J and Sherman M; American Association for the Study of Liver Diseases: Management of hepatocellular carcinoma: An update. Hepatology 53: 1020-1022, 2011.

23. Yang Y, Lim SK, Choong LY, Lee H, Chen Y, Chong PK, Ashktorab H, Wang TT, Salto-Tellez M, Yeoh KG, et al: Cathepsin $\mathrm{S}$ mediates gastric cancer cell migration and invasion via a putative network of metastasis-associated proteins. J Proteome Res 9: 4767-4778, 2010.

24. Tong SW, Yang YX, Hu HD, An X, Ye F, Hu P, Ren H, Li SL and Zhang DZ: Proteomic investigation of 5-fluorouracil resistance in a human hepatocellular carcinoma cell line. J Cell Biochem 113: 1671-1680, 2012.

25. Yang Y, Toy W, Choong LY, Hou P, Ashktorab H, Smoot DT, Yeoh KG and Lim YP: Discovery of SLC3A2 cell membrane protein as a potential gastric cancer biomarker: Implications in molecular imaging. J Proteome Res 11: 5736-5747, 2012.

26. Ho J, Kong JW, Choong LY, Loh MC, Toy W, Chong PK, Wong CH, Wong CY, Shah N and Lim YP: Novel breast cancer metastasis-associated proteins. J Proteome Res 8: 583-594, 2009.

27. Lepiller Q, Abbas W, Kumar A, Tripathy MK and Herbein G: HCMV activates the IL-6-JAK-STAT3 axis in HepG2 cells and primary human hepatocytes. PLoS One 8: e59591, 2013.

28. Tong SW, Yang YX, Hu HD, An X, Ye F, Ren H, Li SL and Zhang DZ: HSPB1 is an intracellular antiviral factor against hepatitis B virus. J Cell Biochem 114: 162-173, 2013.

29. Schmittgen TD and Livak KJ: Analyzing real-time PCR data by the comparative C(T) method. Nat Protoc 3: 1101-1108, 2008.

30. Gan CS, Chong PK, Pham TK and Wright PC: Technical, experimental, and biological variations in isobaric tags for relative and absolute quantitation (iTRAQ). J Proteome Res 6 : 821-827, 2007.

31. Zhou C, Simpson KL, Lancashire LJ, Walker MJ, Dawson MJ, Unwin RD, Rembielak A, Price P, West C, Dive C, et al: Statistical considerations of optimal study design for human plasma proteomics and biomarker discovery. J Proteome Res 11: 2103-2113, 2012

32. Xie TX, Wei D, Liu M, Gao AC, Ali-Osman F, Sawaya R and Huang S: Stat 3 activation regulates the expression of matrix metalloproteinase-2 and tumor invasion and metastasis. Oncogene 23: 3550-3560, 2004.

33. Yu H, Pardoll D and Jove R: STATs in cancer inflammation and immunity: A leading role for STAT3. Nat Rev Cancer 9: 798-809, 2009

34. Yang J, Wezeman M, Zhang X, Lin P, Wang M, Qian J, Wan B, Kwak LW, Yu L and Yi Q: Human C-reactive protein binds activating Fcgamma receptors and protects myeloma tumor cells from apoptosis. Cancer Cell 12: 252-265, 2007.

35. Hefler LA, Concin N, Hofstetter G, Marth C, Mustea A Sehouli J, Zeillinger R, Leipold $\mathrm{H}$, Lass $\mathrm{H}$, Grimm C, et al: Serum C-reactive protein as independent prognostic variable in patients with ovarian cancer. Clin Cancer Res 14: 710-714, 2008 .
36. Xu M, Zhu M, Du Y, Yan B, Wang Q, Wang C and Zhao J: Serum $\mathrm{C}$-reactive protein and risk of lung cancer: A case-control study. Med Oncol 30: 319, 2013.

37. Nozoe T, Matsumata T, Kitamura M and Sugimachi K: Significance of preoperative elevation of serum C-reactive protein as an indicator for prognosis in colorectal cancer. Am J Surg 176: 335-338, 1998.

38. Fujikawa K, Matsui Y, Oka H, Fukuzawa S and Takeuchi $\mathrm{H}$ : Serum C-reactive protein level and the impact of cytoreductive surgery in patients with metastatic renal cell carcinoma. J Urol 162: 1934-1937, 1999.

39. Nozoe T, Saeki H and Sugimachi K: Significance of preoperative elevation of serum C-reactive protein as an indicator of prognosis in esophageal carcinoma. Am J Surg 182: 197-201, 2001.

40. Mantovani A, Allavena P, Sica A and Balkwill F: Cancer-related inflammation. Nature 454: 436-444, 2008.

41. Heikkilä K, Ebrahim S and Lawlor DA: A systematic review of the association between circulating concentrations of $\mathrm{C}$ reactive protein and cancer. J Epidemiol Community Health 61: 824-833, 2007.

42. Tschopp J, Podack ER and Müller-Eberhard HJ: Ultrastructure of the membrane attack complex of complement: Detection of the tetramolecular C9-polymerizing complex C5b-8. Proc Natl Acad Sci USA 79: 7474-7478, 1982

43. Urieli-Shoval S, Linke RP and Matzner Y: Expression and function of serum amyloid A, a major acute-phase protein, in normal and disease states. Curr Opin Hematol 7: 64-69, 2000.

44. Betts JC, Cheshire JK, Akira S, Kishimoto T and Woo P: The role of NF-kappa B and NF-IL6 transactivating factors in the synergistic activation of human serum amyloid A gene expression by interleukin-1 and interleukin-6. J Biol Chem 268: 25624-25631, 1993.

45. Migita K, Kawabe Y, Tominaga M, Origuchi T, Aoyagi T and Eguchi K: Serum amyloid A protein induces production of matrix metalloproteinases by human synovial fibroblasts. Lab Invest 78: 535-539, 1998.

46. Li Y, Cai L, Wang H, Wu P, Gu W, Chen Y, Hao H, Tang K, Yi P, Liu M, et al: Pleiotropic regulation of macrophage polarization and tumorigenesis by formyl peptide receptor-2. Oncogene 30: 3887-3899, 2011

47. Kim H, Meyer K, Di Bisceglie AM and Ray R: Hepatitis C virus suppresses C9 complement synthesis and impairs membrane attack complex function. J Virol 87: 5858-5867, 2013.

48. Chong PK, Lee H, Loh MC, Choong LY, Lin Q, So JB, Lim KH, Soo RA, Yong WP, Chan SP, et al: Upregulation of plasma C9 protein in gastric cancer patients. Proteomics 10: 3210-3221, 2010.

49. Narayanasamy A, Ahn JM, Sung HJ, Kong DH, Ha KS, Lee SY and Cho JY: Fucosylated glycoproteomic approach to identify a complement component 9 associated with squamous cell lung cancer (SQLC). J Proteomics 74: 2948-2958, 2011.

50. Ferrín G, Ranchal I, Llamoza C, Rodríguez-Perálvarez ML, Romero-Ruiz A, Aguilar-Melero P, López-Cillero P, Briceño J, Muntané J, Montero-Álvarez JL, et al: Identification of candidate biomarkers for hepatocellular carcinoma in plasma of HCV-infected cirrhotic patients by 2-D DIGE. Liver Int 34: 438-446, 2013. 